\title{
Pigment Pattern Formation in Zebrafish: A Model for Developmental Genetics and the Evolution of Form
}

\author{
IAN K. QUIGLEY ${ }^{1}$ AND DAVID M. PARICHY ${ }^{1,2 *}$ \\ ${ }^{1}$ Section of Integrative Biology, University of Texas at Austin, Austin, Texas 78712 \\ ${ }^{2}$ Section of Molecular, Cell and Developmental Biology and Institute for Cellular and Molecular Biology University of Texas at \\ Austin, Austin, Texas 78712
}

\begin{abstract}
The zebrafish Danio rerio is an emerging model organism for understanding vertebrate development and genetics. One trait of both historical and recent interest is the pattern formed by neural crest-derived pigment cells, or chromatophores, which include black melanophores, yellow xanthophores, and iridescent iridophores. In zebrafish, an embryonic and early larval pigment pattern consists of several stripes of melanophores and iridophores, whereas xanthophores are scattered widely over the flank. During metamorphosis, however, this pattern is transformed into that of the adult, which comprises several dark stripes of melanophores and iridophores that alternate with light stripes of xanthophores and iridophores. In this review, we place zebrafish relative to other model and non-model species; we review what is known about the processes of chromatophore specification, differentiation, and morphogenesis during the development of embryonic and adult pigment patterns, and we address how future studies of zebrafish will likely aid our understanding of human disease and the evolution of form. Microsc. Res. Tech. 58: 442-455, 2002. @ 2002 Wiley-Liss, Inc.
\end{abstract}

\section{INTRODUCTION}

To generate the adult body plan, cells must differentiate, proliferate, die, and migrate. Despite dramatic advances in understanding these behaviors and their controls during embryogenesis, the cellular and genetic bases for patterning the adult form are largely unknown, particularly in vertebrates. A proper description of these later events in vertebrate development would bring with it deeper knowledge of a variety of far-reaching cellular actions and processes; it would also provide a base from which to study the etiology of human genetic disease and the evolution of adult form across taxa.

A key cell population in vertebrate development comes from the neural crest, a transient embryonic cell type that derives from ectoderm shortly after gastrulation (Erickson and Reedy, 1998; Hörstadius, 1950; Le Douarin, 1982; Nguyen et al., 1998, 2000). Formed at the junction between the neural and epidermal ectoderm, neural crest cells differentiate into a variety of cell types, eventually becoming craniofacial structures, neurons, glial cells, connective tissues, secretory adrenal apparati, and pigment cells (reviewed by Erickson and Reedy, 1998; Groves and Bronner-Fraser, 1999; Hall, 1999).

Of the various cell and tissue types derived from the neural crest, pigment cells (or "chromatophores" in ectothermic vertebrates) are easy to observe because of the pigments that they contain and because the patterns formed by these cells are externally visible. For these reasons, and because of their neural crest origin, pigment cells have received substantial attention both historically (e.g., Lopashov, 1944; Mayer, 1965; Twitty, 1936) and recently as models for unraveling the cellular underpinnings of vertebrate development. Moreover, because pigment cells and pigment patterns are not essential for viability in the laboratory, a large number of genetic mutants have been isolated that affect pigmentation. For example, a variety of pigment mutants were isolated in the eighteenth and nineteenth century by mouse fanciers in Asia and Europe; this wide repertoire of pigment pattern variants proved extremely useful to early twentieth century researchers laying down the foundations of mammalian genetics (see Jackson, 1994). Researchers have also turned to other model organisms for studying pigment cells, including birds and amphibians, though these species typically have not been tractable genetically (e.g., Epperlein and Löfberg, 1990; Parichy, 2001; Richardson et al., 1991). Recent years, however, have seen the emergence of a new, genetically tractable model vertebrate: the zebrafish. Here, we present recent advances in our understanding of pigment cell and pigment pattern formation in zebrafish, and we suggest promising areas for future research.

\section{ZEBRAFISH AS A MODEL ORGANISM}

The zebrafish, Danio rerio, is a small fish from the minnow family (Cyprinidae) with vibrantly colored horizontal stripes and was first described by the British surgeon Francis Hamilton in 1822. Conveniently for developmental biologists and geneticists, zebrafish have transparent and externally developing embryos, and an essentially complete vertebrate body plan is formed by 24 hours of development (though the embryonic/early larval pigment pattern is not fully formed for

\footnotetext{
*Correspondence to: D.M. Parichy, Section of Integrative Biology, University of Texas at Austin, 24th and Speedway, C0930, Austin, TX 78712 .

E-mail: dparichy@mail.utexas.edu

Received 28 December 2001; accepted in revised form 2 February 2002

Grant Sponsor: NIH; Grant number: R01 GM62182-01.

DOI 10.1002/jemt.10162

Published online in Wiley InterScience (www.interscience.wiley.com).
} 

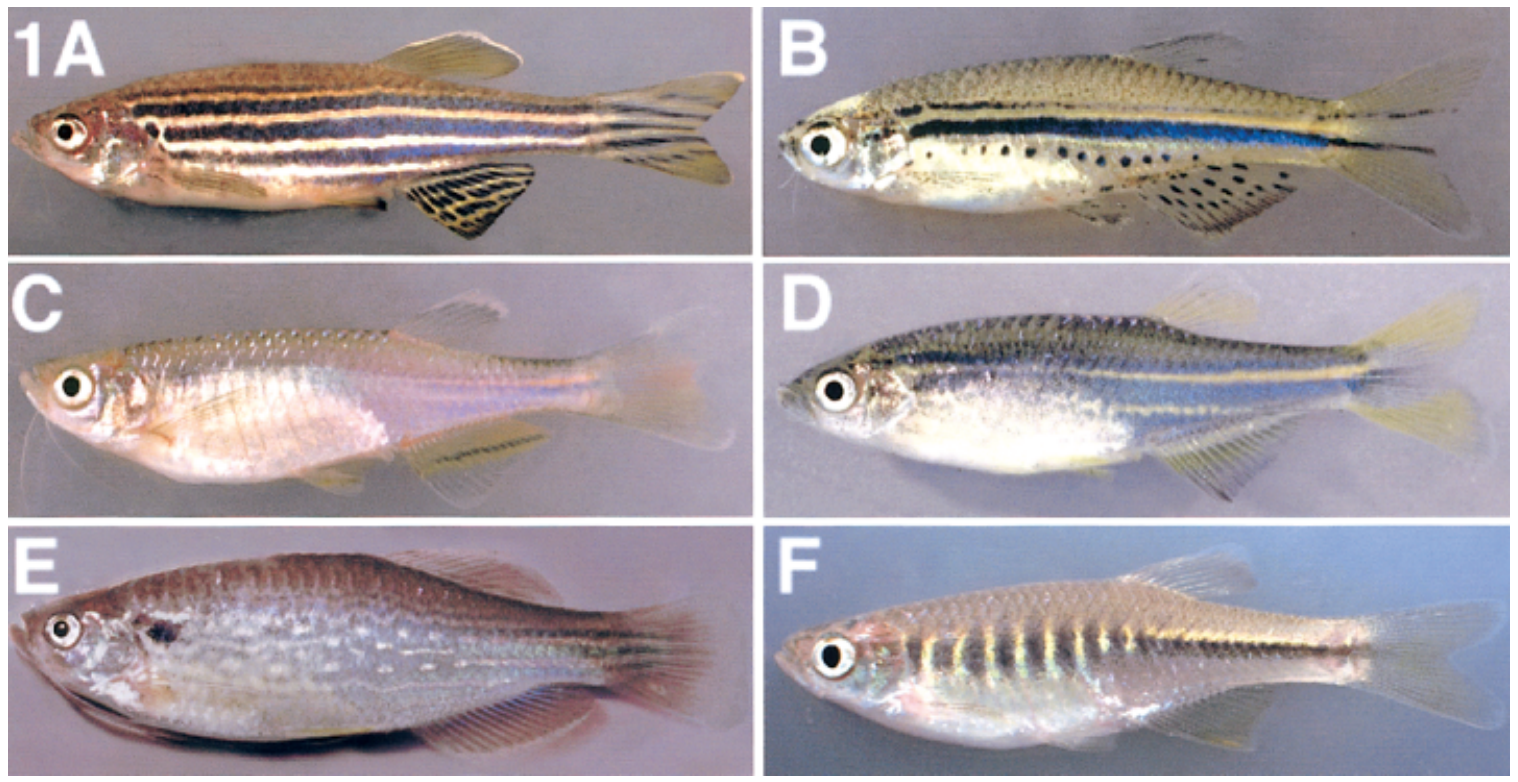

Fig. 1. Diverse pigment patterns of Danio fishes. A: D. rerio. B: D. nigrofasciatus. C: D. albolineatus. D: D. kerri. E: D. dangila. F: D. shanensis.

several more days). Subsequently, the larvae metamorphose quickly into juveniles, and reproductive maturity can be attained in as little as six weeks. Adult zebrafish are easy to care for and breed, and their reproduction is essentially aseasonal in the laboratory. Moreover, large numbers of embryos (50-300) can be obtained from females at intervals of as little as two weeks. Finally, a variety of genomic resources are available for working with zebrafish, including databases of expressed sequence tags, high-density genetic linkage and radiation hybrid maps, and an ongoing effort to sequence the zebrafish genome (Amemiya et al., 1999; Clark et al., 2001; Hukriede et al., 1999; Shimoda et al., 1999; Vogel, 2000). For these reasons, zebrafish have become a model organism for studies of such disparate subjects as immunology, gastrulation, and the function and evolution of visual systems (Kodjabachian et al., 1999; Li, 2001; Trede et al., 2001).

Although recent work emphasizes the zebrafish as a model organism in the laboratory, $D$. rerio occurs in nature, as do 45-50 other described species in the genus Danio, as well as an untold number of undescribed species from India to southeast Asia (Fang, 1997a,b, 1998, 2000; Fang and Kottelat, 1999; McClure, 1999; Parichy and Johnson, 2001). Many of these other danios exhibit similar developmental and life history characteristics to zebrafish. Nevertheless, even species closely related to $D$. rerio differ dramatically in their patterns of pigmentation, exhibiting horizontal stripes of varying numbers and sizes, spots, uniform patterns, vertical bars, and different combinations of these pattern elements (Figs. 1,2). This lends itself to questions of natural variation, the mechanistic bases for the evolution of form, and the nature of reproductive isolation and speciation. Virtually nothing is known about the ecological context and behavioral uses of Danio pigment patterns, though other species

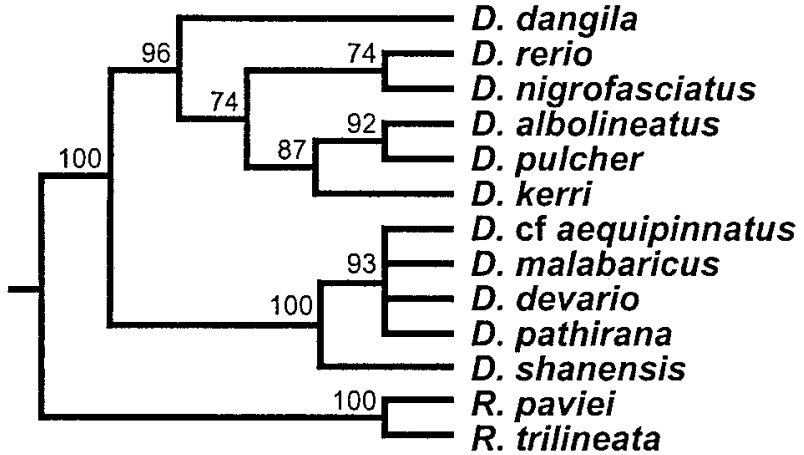

Fig. 2. Phylogenetic relationships among danios. Analyses of mitochondrial rDNA sequences reveals at least two major clades of danios: one clade includes the zebrafish, $D$. rerio, several other small danios, and the large bodied $D$. dangila; a second clade includes several large bodied species, as well as medium sized danios such as D. shanensis (Parichy and Johnson, 2001; Parichy, unpublished data). The phylogenetic positions of numerous other Danio species have yet to be determined.

use their patterns in schooling, recognizing and choosing mates, and avoiding predation (e.g., Endler, 1978; Houde, 1997). It seems reasonable to expect similar roles for the pigment patterns of zebrafish and its relatives; these possibilities are only beginning to be addressed.

\section{OUTLINE OF ZEBRAFISH PIGMENT PATTERN DEVELOPMENT Early Neural Crest Patterning}

As in other vertebrates, induction of the zebrafish neural crest begins during gastrulation and depends on interactions between epidermal and neural ectoderm 
involving a bone morphogenetic protein (Bmp) signaling pathway, and presumably other phylogenetically conserved pathways as well (Dickinson et al., 1995; Liem et al., 1995; Moury and Jacobson, 1990; Nguyen et al., 1998, 2000). These early signals result in the formation of dorsal neural tube cell types, including an equivalence group comprising prospective RohonBeard sensory neurons and prospective neural crest cells. Segregation of most neural crest cell lineages (though not fin mesenchyme thought to be derived from neural crest) depends on deltaA-dependent signaling, presumably via a lateral inhibition mechanism occurring at the open neural plate stage (Cornell and Eisen, 2000). Intriguingly, an insertional mutant in zebrafish, alyron, results in the loss of most neural crest cells and their derivatives, without altering Rohon-Beard development (Cretekos and Grunwald, 1999). Although the gene disrupted in alyron yet to be identified, it acts cell autonomously within the neural crest lineage and could be an important mediator of very early events in neural crest specification. During later development, the definitive, mesenchymal neural crest cells become visible as the neural keel segregates from the epidermis (Raible et al., 1992; Schmitz et al., 1993; Vaglia and Hall, 2000).

Once formed, neural crest cells disperse from their position along the neural tube and migrate widely throughout the embryo. Like other species, this migration occurs in an anterior-to-posterior wave, with cells traveling along either of two major migratory pathways: a ventromedial pathway between the developing neural tube and somites, and a dorsolateral pathway between the somites and overlying epidermis (e.g., Jesuthasan, 1996; Loring and Erickson, 1987; Raible et al., 1992; Vaglla and Hall, 2000). Neural crest cells enter first into the ventromedial pathway, and these cells differentiate into many of their potential lineages, including Schwann cells, sympathetic neurons, sensory neurons, post-ganglionic motor neurons, adrenal chromaffin cells, and chromatophores (Raible and Eisen, 1994, 1996).

Although neural crest cells are initially inhibited from entering the dorsolateral pathway, as evidenced by the collapse of protrusions contacting early stage somites, stable protrusions ultimately form and neural crest cells begin to migrate beneath the epidermis (Jesuthasan, 1996).

In contrast to neural crest cells in the medial pathway, laterally migrating cells have been observed to develop only into chromatophore lineages (Raible and Eisen, 1994; for a potential exception, see Collazo et al., 1994); this bias is common to other vertebrates as well (with the exception of Xenopus, in which neural crest cells simply do not migrate dorsolaterally; Collazo et al., 1993; Erickson et al., 1992; Tucker, 1986). Finally, neural crest cells also enter into the median fin folds of the larva, and neural crest-derived cells as well as chromatophores of presumptive neural crest origin enter the fins of the adult (Dutton et al., 2001; Goodrich et al., 1954; Rawls and Johnson, 2000; Smith et al., 1994).

\section{Repertoire of Pigment Cell Classes in Danios}

During or even prior to their migration, neural crest cells destined for chromatophore lineages begin to differentiate into the three major chromatophore types comprising the early larval pigment pattern. Melanophores, analogous to melanocytes in mammals, produce dark melanin. Xanthophores are yellow or orange cells that contain pteridine pigments and carotenoids. Finally, iridophores are metallic silver or gold cells whose reflectance is imparted by crystalline purine deposits (see reviews in this issue; Bagnara, 1998; Fujii, 1993). During the metamorphosis that transforms the larval phenotype into that of the adult, and during later adult growth and development, additional precursor cells differentiate into the three major classes of chromatophores and also minor classes. These minor classes include white leucophores at the tips of the fins, and reddish erythrophores in the fins and on the body of some danio species (though not zebrafish).

\section{Pigment Patterns and Pattern Elements}

The larval and adult pigment patterns in zebrafish are quite different. Prior to metamorphosis, xanthophores cover the flank and melanophores form four distinct stripes: a dorsal band extending from the head to the tail along the dorsal apex of the myotomes; a lateral band at the level of the horizontal myoseptum; a ventral band, from between the eyes, over the dorsal yolk sac, and to the top of the tail; and a band over the ventral surface of the yolk sac (Fig. 3A; Hisaoka and Battle, 1958; Kimmel et al., 1995; Milos and Dingle, 1978a; Thumann, 1931).

During metamorphosis, the pattern of four stripes in the embryo gradually gives way to the striped pigment pattern of the adult (Johnson et al., 1995; Kirschbaum, 1975; Parichy et al., 2000b; Figs. 3A,4). At the onset of metamorphosis (about two weeks after fertilization), new melanophores appear dispersed over the flank and these cells gradually increase in number. Roughly a week later, melanophore numbers increase more sharply and dark and light stripes of the adult become evident. Initially, two dark "primary" stripes form dorsal and ventral to the horizontal myoseptum, with a light stripe in between; the dark stripes comprise melanophores and iridophores, whereas the light stripe comprises xanthophores and iridophores. During later development over the course of weeks and months, additional "secondary" dark and light stripes are added dorsally and ventrally as the fish continue to grow, with 4-5 dark stripes present in the typical adult zebrafish. Finally, although the striped pattern results from chromatophores deep within the dermis and adjacent to the myotomes, an overall dark cast also is imparted to the dorsal surface by superficial melanophores associated with the dermal scales (Hawkes, 1974; Kirschbaum, 1975).

\section{PIGMENT CELL SPECIFICATION AND DIFFERENTIATION}

The mechanisms of chromatophore specification and differentiation can be broadly characterized as intrinsic-those occurring within the prospective chromatophore, or chromatoblast-and extrinsic, involving communication between the chromatoblast and its extracellular environment. Intrinsic mechanisms include the transcriptional regulation of genes encoding enzymes essential for pigment synthesis, transcriptional regulation of the transcription factors themselves, and, presumably, the silencing of genes that maintain an 


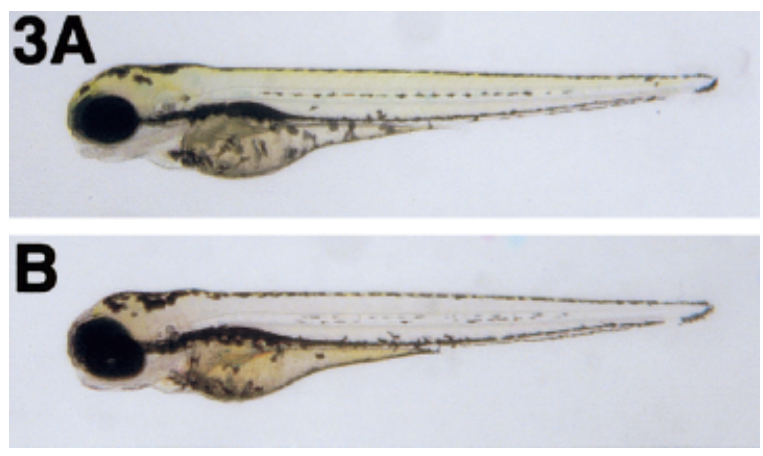

Fig. 3. Wild-type and mutant early larval pigment patterns of zebrafish. A: Wild-type larvae exhibit several stripes of melanophores and iridophores, as well as widely scattered xanthophores. B: fms mutant larvae lack xanthophores, but have normal melanophore and iridophore patterns (see text).

undifferentiated state or promote alternative differentiated states. By contrast, extrinsic factors are likely to include interactions between chromatoblasts and local extracellular matrices, contact-dependent interactions between adjacent cells of chromatophore and non-chromatophore lineages, and perhaps longer range diffusible signals; all of these extrinsic factors depend on transduction of a signal, typically through receptors at the cell surface.

In this section, we consider our understanding of intrinsic factors and extrinsic factors during specification and differentiation of the earliest, multipotent, chromatoblasts, as well as each of the major chromatophore lineages. However, it is important to remember that chromatoblast morphogenesis (treated below) and chromatoblast differentiation may be closely intertwined. For example, the timing and direction of cell migration may expose the cells to different inductive signals. Conversely, cells having different states of specification may exhibit different migratory, proliferative, and survival capabilities (Erickson and Goins, 1995; also see Erickson and Reedy, 1998). Finally, the death of chromatoblasts or their failure to proliferate can be difficult to distinguish from a failure of these cells to differentiate, particularly if the morphogenetic behavior occurs prior to the appearance of markers for the cell type in question (we explicitly address this difficulty in Chromatophore Subpopulations).

\section{Earliest Chromatophore Specification}

Clonal and lineage analyses of neural crest cells have revealed a mixture of multipotent and fate-restricted cells (e.g., Baroffio et al., 1988; Bronner-Fraser and Fraser, 1989; Frank and Sanes, 1991; Henion and Weston, 1997). For zebrafish, Raible and Eisen (1994) showed by labeling individual neural crest cells that clones can differentiate as melanophores alone, other chromatophores alone, or chromatophores and other cell types (e.g., sensory neurons). More recently, Dutton et al. (2001) also showed that individual labeled clones can form either single chromatophore types, dual chromatophore types (melanophore and xanthophore, or melanophore and iridophore), and more rarely, all three chromatophore types (K.A. Dutton and
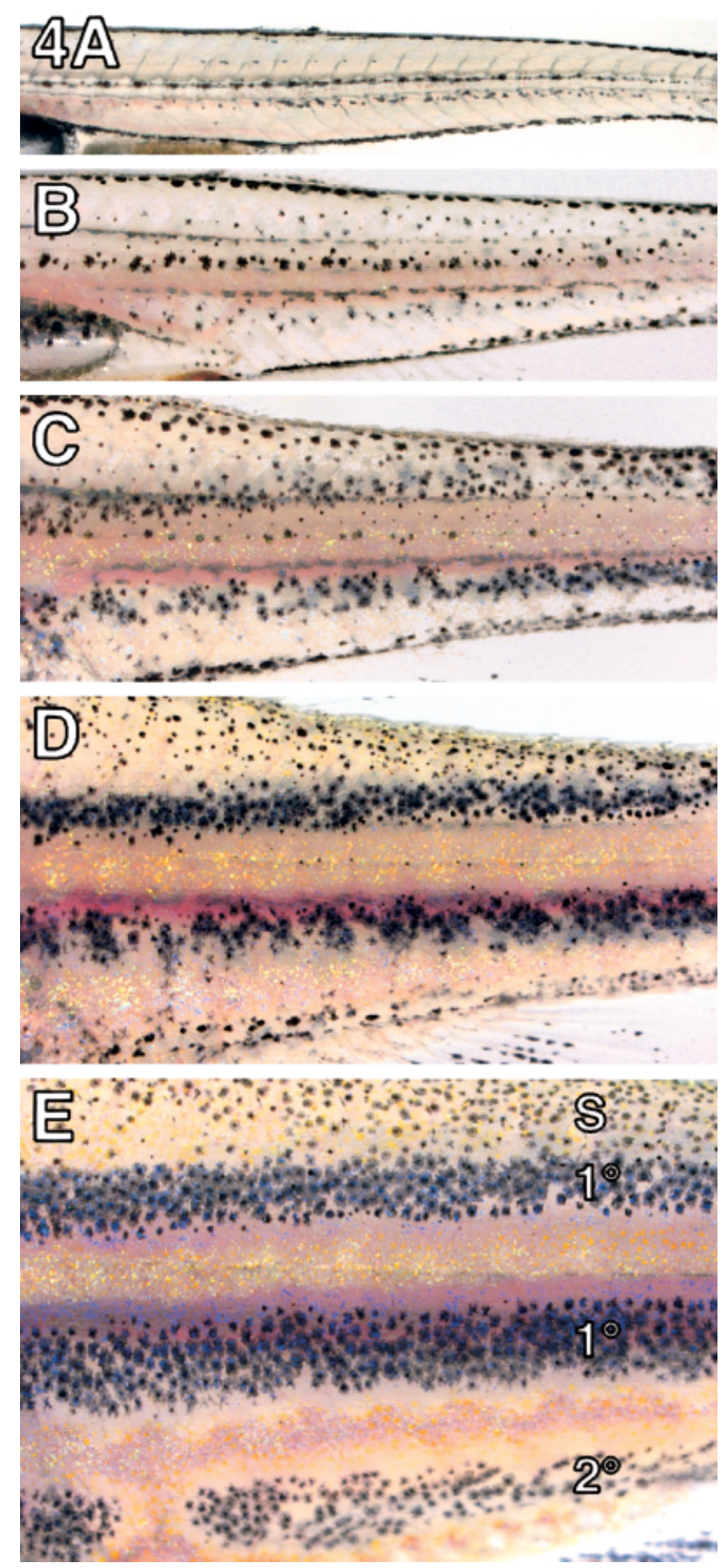

Fig. 4. Metamorphosis of the zebrafish pigment pattern. Shown are a series of images from a single wild-type larva over the course of $25 \mathrm{~d}$ of development. A: The early larval pigment pattern persists for about two weeks. B: Subsequently, melanophores arise dispersed over the flank in regions not previously occupied by these cells. C: During a second phase of metamorphosis, additional melanophores begin to arise in prospective melanophore stripe regions. D: By about 4 weeks of development, two primary adult melanophore stripes border a lighter interstripe region. E: During subsequent growth and development, primary $\left(1^{\circ}\right)$ melanophore stripes become more regular and additional, secondary $\left(2^{\circ}\right)$ stripes are added to the pattern; in this image, a ventral stripe can be seen immediately dorsal to the anal fin. has started to form in this image. Scale melanophores (S) can be seen covering the dorsal flank. 
R.N. Kelsh, personal communication). These data raise the possibility of a single, multipotent "chromatoblast," or chromatophore stem cell, able to generate all three major classes of chromatophores but not fated to produce other neural crest-derivatives. Consistent with this hypothesis is the potential for transdifferentiation among different chromatophore classes (Ide, 1986; Thibidaeau and Holder, 1998; for another example of transdifferentiation among neural crest derivatives, see: Dupin et al., 2000), analyses of molecular marker expression (Luo et al., 2001; Parichy et al., 2000a,b), as well as the isolation of mutants in which cells express characteristics of more than one chromatophore class; e.g., zebrafish parade mutants have cells with characteristics of both melanophores and iridophores (Kelsh et al., 1996). Nevertheless, these observations do not exclude the possibility that some chromatophores may differentiate without passing through a bipotent or tripotent precursor.

Analyses of early states of chromatophore specification and differentiation, that is, prior to the deposition of visible pigment, require molecular markers to distinguish neural crest-derived cells from other unpigmented mesenchymal cells. HNK-1 antibodies have been useful for analyzing neural crest cells in other taxa, including some fishes (e.g., Erickson et al., 1989, 1992; Hou and Takeuchi, 1994), but do not appear to recognize most zebrafish neural crest-derived cells (Metcalfe et al., 1990). Nevertheless, several other markers have been identified. Most notable among these are foxd3 (formerly forkhead-6) and crestin. Foxd3 is a winged helix class transcription factor, and in birds and Xenopus is involved in specifying the neural crest lineage and in repressing the melanocyte lineage (Kos et al., 2001; Sasai et al., 2001). In zebrafish, foxd3 transcripts are detectable in most or all premigratory neural crest cells, but are lost once these cells disperse (Odenthal and Nüsslein-Volhard, 1998). In contrast, crestin was identified as a cyclops-dependent transcript and subsequently was found to have similarity to bhikari-class transposable elements (Rubinstein et al., 2000). Crestin is expressed by premigratory and migrating neural crest-derived cells and its transcript co-localizes with markers identified for all known neural crest derivatives, including chromatophore, neural, and ectomesenchymal classes (Luo et al., 2001). Presumably, the crestin transcript represents a transposable element insertion downstream of a promoter regulating ubiquitous expression in neural crest lineages; the identity and evolutionary fate of the affected locus remain unknown. Together, these and other markers facilitate analyses of cell lineage specification and differentiation, particularly since zebrafish embryos are amenable to monitoring expression of multiple genes simultaneously by two color mRNA in situ hybridization, immunohistochemistry, and other reporter systems (e.g., Dutton et al., 2001; Finley et al., 2001; Miller et al., 2000).

Insights into early, intrinsic events in chromatoblast specification come from thorough and elegant analyses of the zebrafish mutant, colourless. As its name implies, colourless mutant larvae lack nearly all chromatophores, with the exception of a few residual xanthophores (Kelsh et al., 1996, 2000; Kelsh and Eisen, 2000). Anatomical and molecular analyses revealed, in addition, that not only chromatoblasts and chromatophores but all neural derivatives of the neural crest are absent or seriously reduced in these fish; ectomesenchymal derivaties, such as fin mesenchyme and craniofacial cartilages, are unaffected. By transplanting $\mathrm{co}^{-}$ lourless mutant cells to wild-type embryos and vice versa, Kelsh and colleagues also demonstrated that colourless exerts its effects autonomously to the chromatophore (and presumably other non-ectomesenchymal) neural crest lineages. Consistent with this activity, colourless mutants recently have been shown to have lesions in the gene encoding sox10, an HMG-box transcription factor (Dutton et al., 2001). Sox10 was found to be widely expressed in premigratory neural crest, including most but not all cells expressing foxd3. Moreover, iontophoretic labeling of individual neural crest cells showed that the majority of cells in wild-type embryos diverged towards non-ectomesenchymal cell fates. In contrast, colourless/sox10 mutant non-ectomesenchymal cells showed few signs of differentiation at the level of molecular markers or visible cellular phenotypes, typically failed to migrate, and ultimately died by apoptosis about two days post-fertilization. Dutton et al. (2001) propose a model in which sox10 is essential for specifying non-ectomesenchymal neural crest cell fates; in the absence of sox10 function, downstream genes essential for differentiation, migration, and survival (see below) are not transcribed, resulting in the loss of the precursor cells themselves. These findings extend earlier analyses of the Sox10/Dom mutant mouse, in which neural crest and melanocyte lineages are severely reduced and presumptive neural crest-derived cells undergo apoptosis (Potterf et al., 2001; Southard-Smith et al., 1998).

Molecular and genetic analyses in amniotes suggest that expression of other transcription factors, such as Pax3, also identify important, intrinsic steps in the specification of pigment cell and some neuronal neural crest-derived lineages: e.g., Pax3/splotch mutant mice have severe pigment cell deficiencies and lack neural crest-derived enteric neurons (e.g., Hornyak et al., 2001; Mansouri et al., 1996; Potterf et al., 2000). Although zebrafish orthologues for Pax3 and some other transcription factors have been identified and are expressed in at least some premigratory neural crest cells, functional roles for these genes have not been elucidated in fishes (Furthauer et al., 1997; Seo et al., 1998; Thisse et al., 1995).

While specific genes are starting to be described that are essential for intrinsic aspects of chromatophore specification and differentiation, progress also is being made towards understanding the extrinsic signals that promote chromatophore fates. In mouse, double mutants for Wnt-1 and Wnt-3a severely reduce the numbers of neural crest cells, consistent with a role for Wnt signals in stimulating the proliferation of these cells during normal development (Ikeya et al., 1997; also see García-Castro et al., 2002). Dorsky et al. (2000) provided an important addition to these findings by demonstrating an essential role for Wnt signaling in chromatophore specification as well. These authors identified Wnt1/Wnt-3a transcripts in the anterior dorsal neural tube adjacent to neural crest cells fated to become chromatophores, but several cell diameters distant from cells fated to become neural derivatives. To 
test whether this correlation reflected a functional role for Wnts in specifying chromatophore vs. neural fates, embryos were injected with transcripts encoding either a dominant negative Wnt, or a constitutive activator of the downstream Wnt signaling pathway (cytoplasmic $\beta$-catenin). The results clearly showed that disruption of Wnt signaling promotes neural fates, whereas activation of Wnt signaling promotes chromatophore fates. Similar inductive properties have now been demonstrated for amniote Wnts, with the further observation that Bmp signaling antagonizes these effects (Dunn et al., 2000; Jin et al., 2001). Other mediators of chromatoblast specification (or repression) in zebrafish remain to be identified.

\section{Melanophore Lineage}

There is only one kind of pigment cell in amniotes: the melanocyte. Because of the wealth of knowledge about these cells in birds and mammals, we know more about the specification and differentiation of Danio melanophores than other chromatophore classes. In particular, a number of developmental markers for this lineage have been identified in amniotes and these have similar utility for analyzing cell behaviors and states of differentiation in fish. Included among these are genes encoding enzymes for melanin synthesis, such as dopachrome tautomerase (dct, also known as tyrosinase related protein-2), tyrosinase-related protein-1 (Tyrp1), and tyrosinase (e.g., Dunn et al., 2000; Steel et al., 1992). Zebrafish orthologues of dct (Kelsh et al., 2000) and tyrosinase (Camp and Lardelli, 2001) have been identified and both are expressed in presumptive melanoblasts.

A large number of mutants affecting melanin synthesis have been isolated in mouse and a growing number have been cloned. Likewise, zebrafish mutants have been isolated in which melanization is reduced or absent, including albino, golden, and sandy (Kelsh et al., 2000; Lin et al., 1992; Streisinger et al., 1989). Several of these mutations act autonomously within the melanophore lineage, consistent with roles in melanin synthesis or deposition (Lin et al., 1992; Parichy, unpublished data). Once these mutants have been cloned, they will provide molecular markers for identifying different states of melanophore specification and differentiation, and these in turn will allow ordering these genes into pathways. For example, Kelsh et al. (2000) showed that albino, sandy, and several other melanization mutants nevertheless have normal numbers of $d c t+$ melanoblasts, placing the genes corresponding to these mutations downstream of dct. Such analyses have the potential for significantly clarifying melanin synthesis pathways in zebrafish. Particularly interesting will be roles for genes that regulate switching between phaeomelanin (reddish-brown) and eumelanin (black) production in amniotes (Lu et al., 1994; Rees, 2000; Sviderskaya et al., 2001), as zebrafish are only known to produce the latter.

Transcriptional regulation of genes essential for melanophore differentiation is becoming increasingly well understood in zebrafish and other taxa. In mouse, the microphthalmia locus encodes the basic helix-loop-helix transcription factor Mitf, and mutations at this locus reduce melanocyte numbers, likely due to a failure of normal specification, survival, or both (Goding,
2000; Hodgkinson et al., 1993; Opdecamp et al., 1997). Mitf target sites are present upstream of tyrosinase, Tyrp-1, and dct, and Mitf binding at these sites stimulates transcription of these differentiation genes (Bertolotto et al., 1998a,b). Thus, Mitf is a crucial factor in the commitment of cells to the melanophore lineage.

Recently, Lister et al. (1999) showed that the zebrafish mutant nacre results from a lesion in a zebrafish orthologue of Mitf. Nacre/mitfa mutants lack melanophores and melanoblast markers (dct and kit, see below), consistent with a role for this locus in melanoblast specification. These mutants also have fewer xanthophores and somewhat more iridophores, suggesting overlap in genetic dependencies between melanophores and xanthophores and perhaps tradeoffs in allocation between these lineages and iridophores. Intriguingly, nacre/mitfa mutants lacked eye defects typical of mouse Mitf mutants. Lister et al. (2001) recently identified a second Mitf orthologue in zebrafish, mitfb, which is expressed in the eye and other sites of mouse Mitf expression, but is not expressed in melanophores or their precursors. Nevertheless, ectopic expression of mitfb can rescue melanophore development in nacre/ mitfa mutants. These findings suggest that zebrafish mitfa and mitfb arose by gene duplication and current roles for these genes represent subfunctionalization of an ancestral locus (also see Amores et al., 1998; Force et al., 1999; Friedman and Hughes, 2001).

How is mitf regulated to promote melanophore development? In amniotes, evidence is mounting that Mitf transcription is upregulated by Sox10 and Pax3, each of which bind regulatory elements within the Mitf promoter (Potterf et al., 2000, 2001; Watanabe et al., 1998); similar interactions are likely, but not yet demonstrated in zebrafish. Recent analyses also link the transcriptional regulation of mitf to extracellular factors, in particular the Wnt signaling pathway. One result of Wnt signaling is the stabilization of $\beta$-catenin, which translocates to the nucleus and interacts with Tcf/Lef transcription factors to upregulate target gene expression. Dorsky et al. (2000) identified Tcf/Lef binding sites upstream of nacre/mitfa, and demonstrated Lef1 binding to this promoter in vitro. They further demonstrated that $\beta$-catenin upregulates expression of a luciferase reporter gene driven by the nacre/mitfa promoter, and that this effect depended on the presence of the Tcf/Lef binding sites. Finally, they were able to rescue the nacre mutant phenotype with a promoter and cDNA that included these binding sites, but were unable to rescue the mutant when the sites were deleted. An interesting question that remains unresolved is whether roles for Wnt signaling during melanophore development are distinct from roles in specifying precursors to all chromatophore classes.

Observations of melanophores colonizing the horizontal myoseptum during early stages of metamorphosis also suggest extrinsic factors necessary for the differentiation of these cells; if embryonic melanophores fail to colonize a particular somite, additional melanophores differentiate de novo at these unoccupied sites, resulting in an overall regulation of melanophore numbers (Milos and Dingle, 1978a,b; Milos et al., 1983). Nevertheless, the mechanisms underlying these effects remain unclear, and could be explained either by contact inhibition of movement preventing melanoblasts 
from entering an occupied region (Tucker and Erickson, 1986a), or competition between melanoblasts and melanophores for limiting supplies of a trophic or differentiation factor (see below; e.g., Duttlinger et al., 1993).

\section{Xanthophore and Iridophore Lineages}

Less is known about the specification and differentiation of xanthophores and iridophores as compared to melanophores. Manufacture of the pteridine pigments found in xanthophores requires a number of enzymes (Ziegler et al., 2000). Genes encoding two of these, GTP cyclohydrolase (gch) and xanthine dehydrogenase/xanthine oxidase $(x d h / x o d)$, have been cloned in the zebrafish and provide convenient lineage markers for xanthophores and their precursors, though gch also is expressed at lower levels in melanophore precursors (Parichy et al., 2000b; Pelletier et al., 2001). Additionally, a large number of mutants have been identified that affect xanthophore development (Odenthal et al., 1996). Although the genes corresponding to these mutants have yet to be identified, several appear to affect primarily pigment synthesis, based on defects in pteridine complements visible by thin-layer chromatography (Odenthal et al., 1996) and high performance liquid chromatography (Le Guyader and Jesuthasan, 2002).

Virtually nothing is known about the specification and differentiation of iridophores, though a number of mutants have been isolated in which iridophores are reduced or absent. One of these is hagoromo, which have fewer iridophores and disrupted stripes as adults, but no apparent defects in early larvae, hagoromo corresponds to a lesion within the intron of a novel gene encoding an F-box/WD-40 protein (Kawakami et al., 2000), but the cellular bases for the mutant phenotype remain unknown. Several other mutants have reduced or increased numbers of iridophores, or defects in iridophore reflectivity, but none have been analyzed in detail for roles in specification or differentiation of the iridophore lineage (Kelsh et al., 1996; Parichy et al., $2000 a$ ). The eventual identification of factors that promote and maintain the different chromatophore fates, and the extent to which different classes share common developmental determinants, will likely provide valuable new insights into the mechanisms of diversification both at the levels of neural crest cells and organismal coloration.

\section{CHROMATOPHORE SUBPOPULATIONS}

An intriguing problem in the development of zebrafish and other organisms that undergo a metamorphosis is whether or not traits expressed at different stages share common cellular and genetic determinants. In zebrafish, the pigment patterns expressed in larvae and adults are very different; it might be supposed that different chromatophores comprise the patterns at different stages, and that the cells might have different genetic requirements. Indeed, metamorphosis is generally assumed to "decouple" traits expressed at different stages of development (Haldane, 1932; Moran, 1994). Nevertheless, very few studies have explicity examined whether the same genes or different genes are required by a trait expressed at different
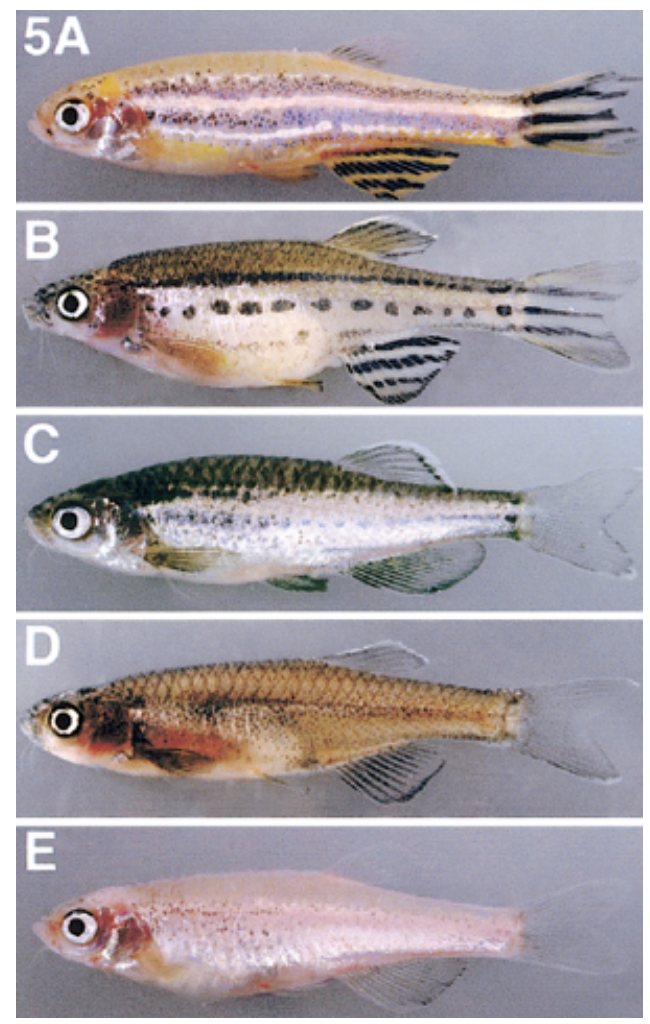

Fig. 5. Zebrafish mutants identify distinct subpopulations of melanophores comprising the adult pigment pattern. A: sparse/kit. B: roselendothelin receptor $b l$. C: panther/fms. D: fms; ednrb1 double mutant. E: fms; kit double mutant. See text for details.

stages, or whether different cell populations are recruited in the production of larval and adult traits.

Some insights into differing genetic dependencies across stages have come from analyses of several zebrafish mutants. In an initial study, the development of melanophore patterns in three mutants-sparse, rose, and leopard-was compared to wild-type (Johnson et al., 1995). Adults of each of these mutants have about half the wild-type complement of stripe melanophores; sparse mutant adults also lack superficial scale melanophores, and consequently exhibit a lighter dorsum than wild-type (Fig. 5A,B). Nevertheless, counts of melanophores during the development of the adult patterns revealed clear differences among mutants. sparse mutants had fewer melanophores in the early larval pattern and subsequently lost all of their melanophores by early stages of metamorphosis; however, the fish regained melanophores during late stages of metamorphosis. In contrast, rose and leopard mutants exhibited normal numbers of melanophores from embryonic to early metamorphic stages, but never exhibited the sharp increase in melanophore numbers normally observed late in metamorphosis. These different temporal patterns of melanophore appearance suggested the possibility that sparse on the one hand, and rose and leopard on the other, might identify temporally and genetically distinct melanophore populations. Consistent with this notion, fish doubly mutant for sparse and rose, or sparse and leopard, lacked virtually all mela- 
nophores, whereas fish doubly mutant for rose and leopard did not have significantly fewer melanophores than the single mutants. These findings raised the possibility that the adult melanophore pattern of zebrafish comprises two genetically distinct subpopulations of melanophores: an early developing subpopulation dependent on sparse, and a later developing subpopulation dependent on rose and leopard.

More recently, the sparse and rose genes have been identified at the molecular level. sparse corresponds to a zebrafish orthologue of kit (Parichy et al., 1999), which encodes a type III receptor tyrosine kinase long known in amniotes to have essential roles in melanocyte morphogenesis (see below). Kit is the cell surface receptor for Mast Cell Growth Factor (Mgf), also known as Kit Ligand or Steel Factor. Mouse mutants for Kit or $M g f$ have melanophore deficiencies and are also severely anemic and sterile owing to defects in hematopoiesis and primordial germ cell migration, respectively (e.g., Besmer et al., 1993; Giebel and Spritz, 1991; Marklund et al., 1998; Nocka et al., 1990). Zebrafish kit is expressed by melanophores and their precursors at embryonic and metamorphic stages, and acts in a cell autonomous manner to promote their development. Unlike mouse mutants for Kit, even null alleles of zebrafish kit lack gross defects in hematopoiesis and are fully fertile (Parichy et al., 1999).

In turn, rose corresponds to a zebrafish orthologue of endothelin receptor b (ednrb1; Parichy et al., 2000a), which encodes a heptahelical G-protein-coupled cell surface receptor, also long studied for its role in the development of amniote melanocytes (e.g., Baynash et al., 1994; Hosoda et al., 1994; Shin et al., 1999; Yoshida et al., 1996). Ednrb binds small peptides termed endothelins, and both endothelin-1 and endothelin-3 have been shown to promote melanocyte development in amniotes (Reid et al., 1996; Takasuka et al., 1994). Zebrafish ednrb1 is expressed during embryonic development and during pigment pattern metamorphosis by melanophores and their precursors, as well as xanthophore precursors and iridophores. Unlike mouse mutants for Ednrb, which exhibit megacolon due to an absence of distal, neural crest-derived enteric neurons, zebrafish ednrb1 mutants show no gross defects in gut development.

In mouse, null alleles of both kit and ednrb eliminate all melanocytes; thus it is somewhat unexpected that these loci are required by only specific subpopulations of zebrafish melanophores. Conceivably, additional paralogues of kit and ednrb with stage-specific activities might be present in the zebrafish genome. Consistent with this notion are similar findings for other genes (e.g., mitfa and mitfb), as well as the identification of two Ednrb loci in avian embryos, one that is expressed during early stages of melanoblast development, and one that is expressed during later stages of melanoblast migration (Lecoin et al., 1998). Additional insights into this possibility will come as the completed zebrafish genome sequence becomes available. Alternatively, the stage-dependence of melanophores on kit and ednrb1 in zebrafish could be fundamentally different from mouse (but see: Jordan and Jackson, 2000b). It will be interesting to determine whether similar stage-specific requirements for these loci are present in other danios and other vertebrates that undergo metamorphosis, such as salamanders (e.g., Parichy, 1998).

A basic difference with mammalian development is also revealed by analyses of another mutant, panther (Parichy et al., 2000b). Mutant larvae exhibit an absence of xanthophores but otherwise normal pigment patterns (Fig. 3B). In contrast, adults lack xanthophores and also exhibit severe defects in both melanophore number and stripe development (Fig. 5C). Molecular analysis revealed that panther corresponds to a zebrafish orthologue of $f m s$, which encodes another type III receptor tyrosine kinase, and is the closest known homologue of kit. Whereas fins in amniotes has roles in osteoclast development and hematopoiesis, it has not been shown to function in neural crest or pigment pattern development and mouse mutants for the Fms ligand, Colony Stimulating Factor-1, display normal pigmentation (Marks and Lane, 1976). Unlike kit and ednrb1, zebrafish FMS shares some pleiotropic effects with mammalian Fms, including defects in osteoclast and macrophage development (Herbomel et al., 2001; Parichy et al., 2000b). Analysis of the timing of melanophore appearance in fms mutant larvae showed a more severe deficit during late stages of metamorphosis, similar to ednrb1 mutants and in contrast to kit mutants. To test whether fms is required for the development of ednrb1-dependent melanophores, but not kit-dependent melanophores, fish doubly mutant for fms; ednrb1 and fms; kit were constructed. These analyses revealed no significant reduction in melanophore number in fms; ednrb1 mutants compared to either single mutant alone (though melanophores adopt a more dispersed pattern; Fig. 5D). Yet, dramatic reductions in melanophore numbers were seen in fms; kit mutants, consistent with additive effects of the two mutations (Fig. 5E). These data suggest the presence of kit-dependent, but fms- and ednrbindependent melanophore subpopulations that arise in embryos and also in early stages of metamorphosis, and a kit-independent but fms-, ednrb1-dependent melanophore subpopulation that arises during late stages of metamorphosis.

Distinct subpopulations of other chromatophore classes may be present as well. For example, ednrb1 and hagoromo mutants lack adult iridophores, but not embryonic iridophores, whereas shady mutants lack embryonic iridophores but not adult iridophores. Compartmentalization of chromatophore lineages across stages may have been a significant factor in allowing pigment pattern changes across life cycles, and evolutionary changes across species.

Finally, the mechanisms by which kit, ednrb1, and fms promote the development of distinct subpopulations of melanophores (and iridophores) remain largely unknown. One possibility is that effects of these genes reflect functions in proliferation or survival (see below). Alternatively, melanophore deficits could reflect functions for these loci in specification or differentiation. An absolute requirement for these genes in specification seems unlikely; e.g., kit mutants have apparently normal numbers of $d c t+$ melanoblasts at embryonic stages (Kelsh et al., 2000), and fms mutants develop gch + and $x d h+$ xanthoblasts (Parichy et al., 2000b). Nevertheless, it is conceivable that signal transduction pathways downstream of these genes act synergistically 
with other factors to promote chromatophore specification or differentiation. Analyses of fin melanophore stripe regeneration following fin amputation are consistent with this notion: whereas wild-type fish recruit new $d c t+$ melanoblasts and melanophores during regeneration, kit null mutants fail to do so (Rawls and Johnson, 2000). Analyses of the temporal requirements for kit using a temperature-sensitive allele further showed that Kit is not essential for establishing a population of "stem cells" competent to differentiate as melanoblasts or melanophores during fin regeneration. Rather, Kit is required during relatively late stages of melanophore development (Rawls and Johnson, 2001), possibly including roles in terminal differentiation. Temporal requirements for kit in the development of melanophore stripes on the body remain unknown.

How might signaling through these cell surface receptors affect melanoblast specification and differentiation? Analyses of zebrafish and amniote mitf promoters reveal cAMP response elements that bind CRE binding protein (CREB; Dorsky et al., 2000; Fuse et al., 1996). CREB is phosphorylated and activated by signal transduction cascades downstream of cell surface receptors, including heptahelical G-protein coupled receptors (like Ednrb) and type III receptor tyrosine kinases (like Kit and Fms), and CREB binding upregulates Mitf transcription (Price et al., 1998b; Schinelli et al., 2001). Recently, a separate pathway has also been shown to link Mitf activity with Kit and Fms: signal transduction through Kit or Fms phosphorylates Mitf and also phosphorylates the transcriptional coactivator p300/CBP (Hemesath et al., 1998; Price et al., 1998a; Weilbaecher et al., 2001). These effects can synergize to promote expression of tyrosinase and other genes involved in differentiation, though phosphorylated Mitf is also targeted for more rapid degradation making the cellular outcome complex and probably context-dependent (Goding, 2000; Hou et al., 2000; Wu et al., 2000). Fuller analyses of these effects will be needed to unravel potential roles for kit, ednrb1, and fms, in promoting the specification and differentiation of chromatophore lineages in zebrafish.

\section{MECHANISMS OF PIGMENT CELL MORPHOGENESIS}

Patterning is not complete once neural crest cells mature into their individual lineages: pattern formation requires not only the specification and differentiation of chromatophore lineages, but their morphogenesis as well. In general, morphogenetic mechanisms include cellular proliferation, migration, maintenance, and death. Here, we examine what is known about the morphogenesis of chromatophores and their precursors during larval and adult pigment pattern development.

\section{Proliferation of Chromatophores and Chromatoblasts}

Although chromatophore numbers increase during zebrafish pigment pattern development, roles for proliferation of chromatophores and chromatoblasts remain unclear. A potential role for kit in promoting the proliferation of embryonic melanoblasts is suggested by analyses of embryonic and adult melanophore numbers (Johnson et al., 1995; Parichy et al., 1999), but not the numbers of embryonic $d c t+$ melanoblasts (Kelsh et al., 2000). Potential roles for kit and ednrb1 in promoting melanoblast proliferation also are implied by studies of amniotes (Dunn et al., 2000; Kunisada et al., 1998; Lahav et al., 1998; Mackenzie et al., 1997), though the extent to which these effects contribute to the adult phenotypes of kit and ednrb1 mutant zebrafish remain unknown. Time-lapse and other analyses now underway should provide new insights into roles for proliferation of chromatoblasts and chromatophores during zebrafish pigment pattern development.

\section{Migratory Behavior of Cells During Pattern Formation}

In amniote embryos, neural crest cells depend on Bmp signaling for the initiation of migration (SelaDonenfeld and Kalcheim, 2000), and various extracellular cues help to determine pathway choice and subsequent behavior (e.g., Oakley et al., 1994; Perissonotto et al., 2000; Santiago et al., 2002; Thomas and Yamada, 1992). Several factors also have been identified as likely contributors to the migratory behavior of melanophores and xanthophores in amphibian embryos, including interactions within and among chromatophore classes, interactions with other cell types and, interactions with extracellular matrices (Epperlein and Löfberg, 1990; Parichy, 1996c, 2001; Tucker, 1986; Tucker and Erickson, 1986a,b). In contrast, the triggers for dispersal and migratory cues for zebrafish neural crest cells and chromatophores remain largely unknown.

Parallel roles for kit and fms in promoting migration of melanophores and xanthophore precursors are suggested by the distribution of these cell types in mutants. In kit mutant larvae, melanophores are found principally near their sites of origin, along the dorsal neural tube and posterior to the otocysts, and few occur ventrally or anteriorly over the head (Parichy et al., 1999). Recent analyses of mouse support a role for Kit in promoting melanoblast motility, independent of other morphogenetic effects (Jordan and Jackson, 2000a; Wehrle-Haller et al., 2001; Wehrle-Haller and Weston, 1995; but see Lecoin et al., 1995; Mackenzie et al., 1997). Like kit mutants, fms mutants develop gch + and $x d h+$ xanthoblasts, but these cells are confined to their sites of origin along the dorsal neural tube and at the midbrain-hindbrain boundary where they originate (Parichy et al., 2000b). The defect in macrophage migration in fms mutants (Herbomel et al., 2001) also is consistent with a role for this gene in promoting xanthoblast migration, independent of effects on survival or differentiation.

Roles for chromatophore migration during pigment pattern metamorphosis have been revealed through image analyses in which individual cells were tracked over periods of up to three weeks (Milos and Dingle, 1978a; Parichy et al., 2000b, unpublished data). During early pigment pattern metamorphosis, melanophores colonizing the horizontal myoseptum appear to be contact inhibited, contributing to a relatively even distribution of these cells (Milos and Dingle, 1978a). During later stages, melanophores that initially appear dispersed over the flank gradually coalesce into the primary melanophore stripes of the juvenile pigment pattern (Parichy et al., 2000b; Fig. 4). Interestingly, melanophores in fms mutants migrate, but fail to do so in a 
directional manner, contributing to the disrupted stripes present in adults (Fig. 5C). Since fms is not expressed by melanophores at these stages, other mechanisms must be suggested to account for the failure of normal melanophore patterning. One possibility is that melanophores normally interact with $\mathrm{fms}$-dependent xanthophores to promote stripe formation. Similar interactions between melanophores and xanthophores have been demonstrated in amphibians (Parichy, 1996a,b), and are also suggested by analyses of fin stripe regeneration (Goodrich et al., 1954).

\section{Cell Death and Survival as Pattern Determinants}

Besides mechanisms for increasing the numbers of chromatophores (differentiation and proliferation) and getting the cells to the right place at the right time (migration), pigment patterns depend on the appropriate survival of cells in some places, and their selective removal by death in others. A clear example of the requirement for proper maintenance comes from kit mutant larvae. Although kit mutant embryos develop melanophores (albeit at reduced numbers), over a period of several days these cells undergo apoptosis and are extruded from the skin, so that by early metamorphosis no melanophores are present (Parichy et al., 1999). A similar maintenance requirement for kit has been demonstrated during fin regeneration: newly differentiated melanophores die when Kit function is ablated (Rawls and Johnson, 2001), consistent with previous analyses in amniotes (Cable et al., 1995; Ito et al., 1999; Okura et al., 1995; Wehrle-Haller and Weston, 1995).

During pigment pattern metamorphosis, selective survival and death of melanophores appear to be necessary for proper stripe formation. Image analyses of pigment pattern metamorphosis in wild-type larvae revealed the death of some melanophores that were located in the middle of the flank (i.e., in the interstripe region between prospective primary melanophore stripes). Relatively little melanophore death occurred in prospective dorsal and ventral melanophore stripe regions (Parichy et al., 2000b; Parichy, unpublished data). These findings are readily interpretable in the context of "clearing" melanophores from a prospective interstripe region, and are concordant with analyses of fin stripe regeneration in which melanophores fragmented and disappeared from regions fated to have xanthophore stripes (Goodrich and Nichols, 1931; Goodrich et al., 1954; Goodrich and Greene, 1959). In contrast, fms mutants exhibit a disorganized pattern of melanophore death: frequencies of death were similar to wild-type in the middle of the flank, but considerably greater than wild-type in dorsal and ventral regions (Parichy et al., 2000b). Thus, fms mutants exhibit both disorganized melanophore migration and melanophore death. A possible explanation for the increased frequency of melanophore death in fms mutants invokes the existence of community effects among melanophores: in the absence of normal migration, local melanophore densities may stochastically fail to reach a critical threshold for maintaining these cells, resulting in the death of melanophores at inappropriate locations. Similar community effects among melanoblasts have been inferred from analyses of the patchwork mutant mouse (Aubin-Houzelstein et al., 1998). Production of paracrine trophic factors by melanoblasts and melanophores could explain these effects in fish and mouse; support for this possibility comes from the observation that avian and salamander chromatophores express both Steel Factor and its receptor, Kit (Guo et al., 1997; N. Parker, personal communication).

\section{PROSPECTS FOR THE FUTURE}

The different processes of neural crest cell and chromatophore specification, differentiation, and morphogenesis that manifest themselves during normal development also are relevant to human genetic diseases in which these same processes can go awry. Indeed, the growing collection of zebrafish mutants provides an opportunity to study several human diseases in a genetically and developmentally tractable model vertebrate. For example, variants of human EDNRB are associated with Hirschsprung disease 2 and Waardenburg-Hirschsprung disease, both characterized by aganglionic megacolon owing to a failure of neural crest-derived enteric neurons to colonize the bowel. Likewise both MITF and SOX10 lesions are associated with Waardenburg syndrome, in which megacolon is accompanied by pigmentary deficiencies and craniofacial abnormalities. Finally, lesions in KIT are associated with the benign melanocyte deficiencies seen in human piebaldism, and lesions in CSF1 (encoding the Fms ligand) are associated with osteopetrosis due to a failure of osteoclast development and normal bone resorption (Amiel and Lyonnet, 2001; Spritz, 1997; Teitelbaum, 2000). Since many zebrafish mutants seem to have fewer pleiotropic effects and hence increased viability relative to their amniote counterparts, zebrafish represent an especially promising model organism for studying the etiology of human genetic diseases. It seems likely that additional zebrafish models for human disease syndromes will be identified as the genome is sequenced and additional mutants are identified at the molecular level.

Finally, zebrafish also offer an opportunity to better understand mechanisms underlying the evolution of form. As alluded to in the introduction, a variety of pigment patterns are observed in other danios (Figs. 1, 2 ). The close phylogenetic relationships of these species means they often can be hybridized in the laboratory, allowing for genetic analyses of pigment pattern diversification. For example, Parichy and Johnson (2001) found that despite the pigment pattern differences between zebrafish $D$. rerio, $D$. albolineatus, D. kerri, $D$. nigrofasciatus, and $D$. dangila, hybrids of all of these species with zebrafish expressed pigment patterns more closely resembling the zebrafish pigment pattern than the heterospecific danio. These findings indicate that alleles of pigment pattern genes in these other species typically are recessive to zebrafish alleles, and raise the possibility that pigment pattern evolution may have occurred largely through the evolution of gain-of-function alleles in zebrafish, or loss-of-function alleles in the other danios. Moreover, because the phenotypes of several zebrafish mutants resemble the naturally occurring phenotypes of other danios, these mutants identify a priori candidate genes that may have contributed to pigment pattern differences between species. For example, ednrb1 mutant $D$. rerio exhibit 
stripes and spots similar to D. nigrofasciatus (Figs. 1B, 5B), whereas fms mutant $D$. rerio exhibit dispersed melanophores similar to D. albolineatus (Figs. 1C, 5C). These observations suggested that interspecific complementation tests could be used to assess whether a gene affected in a zebrafish mutant is the same gene that differs between zebrafish and a heterospecific danio. In an initial demonstration of this approach, a small set of mutants were crossed to these other danios, and the phenotypes of the resulting hybrids compared to those of control hybrids with wild-type zebrafish. This analysis excluded several good candidate genes from having major effect roles in generating pigment pattern differences between species, as the mutant hybrids resembled wild-type control hybrids. In contrast, hybrids between $D$. albolineatus and $\mathrm{fms}$ mutant zebrafish lacked stripes, similar to D. albolineatus, identifying fms as an especially good candidate gene for mediating this interspecific difference. Additional tests of this hypothesis are now being conducted. It seems likely that a deeper appreciation for these mechanisms of interspecific diversification will be made possible both by isolation of additional zebrafish mutants, as well as other approaches facilitated by the genomic resources rapidly becoming available for zebrafish.

\section{ACKNOWLEDGMENTS}

The authors thank an anonymous reviewer for comments on the manuscript. IQ and unpublished results have been supported by NIH RO1 GM62182-01 to D.M.P.

\section{REFERENCES}

Amemiya CT, Zhong TP, Silverman GA, Fishman MC, Zon LI. 1999. Zebrafish YAC, BAC, and PAC genomic libraries. Methods Cell Biol 60:235-258.

Amiel K., Lyonnet S. 2001. Hirschsprung disease, associated syndromes, and genetics: a review. J Med Genet 38:729-739.

Amores A, Force A, Yan YL, Joly L, Amemiya C, Fritz A, Ho RK, Langeland J, Prince V, Wang YL, Westerfield M, Ekker M, Postlethwait JH. 1998. Zebrafish hox clusters and vertebrate genome evolution. Science 282:1711-1714.

Aubin-Houzelstein G, Bernex F, Elbaz C, Panthier J-J. 1998. Survival of patchwork melanoblasts is dependent upon their number in the hair follicle at the end of embryogenesis. Dev Biol 198:266-276.

Bagnara JT. 1998. Ch. 2. Comparative anatomy and physiology of pigment cells in nonmammalian tissues. In: Nordland JJ, Boissy RE, Hearing VJ, King RA, Ortonne JP, editors. The pigmentary system: physiology and pathophysiology. New York: Oxford University Press; p. 9-40.

Baroffio A, Dupin E, Le Douarin NM. 1988. Clone-forming ability and differentiation potential of migratory neural crest cells. Proc Natl Acad Sci USA 85:5325-5329.

Baynash AG, Hosoda K, Giaid A, Richardson JA, Emoto N, Hammer RE, Yanagisawa M. 1994. Interaction of endothelin-3 with endothelin-B receptor is essential for development of epidermal melanocytes and enteric neurons. Cell 79:1277-1285.

Bertolotto C, Abbe P, Hemesath TJ, Bille K, Fisher DE, Ortonne JP, Ballotti R. 1998a. Microphthalmia gene product as a signal transducer in cAMP-induced differentiation of melanocytes. J Cell Biol 142:827-835.

Bertolotto C, Busca R, Abbe P, Bille K, Aberdam E, Ortonne JP, Ballotti R. 1998b. Different cis-acting elements are involved in the regulation of TRP 1 and TRP 2 promoter activities by cyclic AMP: pivotal role of M boxes (GTCATGTGCT) and of microphthalmia. Mol Cell Biol 18:694-702.

Besmer P, Manova K, Duttlinger R, Huang EJ, Packer A, Gyssler C, Bachvarova RF. 1993. The kit-ligand (steel factor) and its receptor $c-k i t / W$ : pleiotropic roles in gametogenesis and melanogenesis. Development (Suppl) 1993:125-137.

Bronner-Fraser M, Fraser S. 1989. Developmental potential of avian neural trunk crest cells in situ. Neuron 3:755-766.
Cable J, Jackson IJ, Steel KP. 1995. Mutations at the $W$ locus affect survival of neural crest-derived melanocytes in the mouse. Mech Dev 50:139-150.

Camp E, Lardelli M. 2001. Tyrosinase gene expression in zebrafish embryos. Dev Genes Evol 211:150-153.

Clark MD, Hennig S, Herwig R, Clifton SW, Marra MA, Lehrach H, Johnson SL, Group tW. 2001. An oligonucleotide fingerprint normalized and expressed sequence tag characterized zebrafish cDNA library. Genome Res 11:1594-1602.

Collazo A, Bronner-Fraser M, Fraser SE. 1993. Vital dye labelling of Xenopus laevis trunk neural crest reveals multipotency and novel pathways of migration. Development 118:313-376.

Collazo A, Fraser SE, Mabee PM. 1994. A dual embryonic origin for vertebrate mechanoreceptors. Science 264:426-430.

Cornell RA, Eisen JS. 2000. Delta signaling mediates segregation of neural crest and spinal sensory neurons from zebrafish lateral neural plate. Development 127:2873-2882.

Cretekos CJ, Grunwald DJ. 1999. alyron, an insertional mutation affecting early neural crest development in zebrafish. Dev Biol 210:322-338.

Dickinson MA, Seleck MAJ, McMahon AP, Bronner-Fraser M. 1995. Dorsalization of the neural tube by the non-neural ectoderm. Development 121:2099-2106.

Dorsky RI, Raible DW, Moon RT. 2000. Direct regulation of nacre, a zebrafish MITF homolog required for pigment cell formation, by the Wnt pathway. Genes Dev 14:158-162.

Dunn KJ, Williams BO, Li Y, Pavan WJ. 2000. Neural crest-directed gene transfer demonstrates Wnt1 role in melanocyte expansion and differentiation during mouse development. Proc Natl Acad Sci USA 97:10050-10055.

Dupin E, Glavieux C, Vaigot P, Le Douarin NM. 2000. Endothelin 3 induces the reversion of melanocytes to glia through a neural crestderived glial-melanocytic progenitor. Proc Natl Acad Sci USA 97: 7882-7887.

Duttlinger R, Manova K, Chu TY, Gyssler C, Zelenetz AD, Bachvarova $R F$, Besmer P. 1993. W-sash affects positive and negative elements controlling c-kit expression: ectopic c-kit expression at sites of kit-ligand expression affects melanogenesis. Development 118:705-717.

Dutton KA, Pauliny A, Lopes SS, Elworthy S, Carney TJ, Rauch J, Geisler R, Haffter P, Kelsh RN. 2001. Zebrafish colourless encodes sox10 and specifies non-ectomesenchymal neural crest fates. Development 128:4113-4125.

Endler JA. 1978. A predator's view of animal color patterns. Evol Biol $11: 319-364$.

Epperlein HH, Löfberg J. 1990. The development of the larval pigment patterns in Triturus alpestris and Ambystoma mexicanum. Adv Anat Embryol Cell Biol 118.

Erickson CA, Goins TL. 1995. Avian neural crest cells can migrate in the dorsolateral path only if they are specified as melanocytes. Development 121:915-924.

Erickson CA, Reedy MV. 1998. Neural crest development: the interplay between morphogenesis and cell differentiation. Curr Topics Dev Biol 40:177-209.

Erickson CA, Loring JF, Lester SM. 1989. Migratory pathwys of HNK-1-immunoreactive neural crest cells in the rat embryo. Dev Biol 134:112-118.

Erickson CA, Duong TD, Tosney KW. 1992. Descriptive and experimental anaysis of the dispersion of neural crest cells along the dorsolateral path and their entry into ectoderm in the chick embryo. Dev Biol 151:251-272.

Fang F. 1997a. Danio maetaengensis, a new species of cyprinid fish from northern Thailand. Ichthyol Explor Freshwaters 8:41-48.

Fang F. 1997b. Redescription of Danio kakhienensis, a poorly known cyprinid fish from the Irrawaddy basin. Ichthyol Explor Freshwaters $7: 289-298$.

Fang F. 1998. Danio kyathit, a new species of cyprinid fish from Myitkyina, northern Myanmar. Ichthyol Explor Freshwaters 8:273-280.

Fang F. 2000. Barred Danio species from the Irrawaddy River drainage (Teleostei, Cyprinidae). Ichthyol Res 47:13-26.

Fang F, Kottelat M. 1999. Danio species from northern Laos, with descriptions of three new species (Teleostei: Cyprinidae). Ichthyol Explor Freshwaters 10:281-295.

Finley KR, Davidson AE, Ekker SC. 2001. Three-color imaging using fluorescent proteins in living zebrafish embryos. Biotechniques 31 : $66-70,72$.

Force A, Lynch M, Pickett FB, Amores A, Yan Y-L, Postlethwait J. 1999. Preservation of duplicate genes by complementary, degenerative mutations. Genetics 151:1531-1545. 
Frank E, Sanes JR. 1991. Lineage of neurons and glia in chick dorsal root ganglia: analysis in vivo with a recombinant retrovirus. Development 111:895-908.

Friedman R, Hughes AL. 2001. Pattern and timing of gene duplication in animal genomes. Genome Res 11:1842-1847.

Fujii R. 1993. Cytophysiology of fish chromatophores. Int Rev Cytol 143:191-255

Furthauer M, Thisse C, Thisse B. 1997. A role for FGF-8 in the dorsoventral patterning of the zebrafish gastrula. Development 124:4253-4264.

Fuse N, Yasumoto K, Suzuki H, Takahashi K, Shibahara S. 1996. Identification of a melanocyte-type promoter of the microphthalmia-associated transcription factor gene. Biochem Biophys Res Commun 219:702-707.

García-Castro MI, Marcelle C, Bronner-Fraser M. 2002. Ectodermal Wnt function as a neural crest inducer. Science 297:848-851.

Giebel LB, Spritz RA. 1991. Mutation of the KIT (mast/stem cell growth factor receptor) protooncogene in human piebaldism. Proc Natl Acad Sci 88:8696-8699.

Goding CR. 2000. Mitf from neural crest to melanoma: signal transduction and transcription in the melanocyte lineage. Genes Dev 14:1712-1728.

Goodrich HB, Greene JM. 1959. An experimental analysis of the development of a color pattern in the fish Brachydanio albolineatus Blyth. J Exp Zool 141:15-45.

Goodrich HB, Nichols R. 1931. The development and the regeneration of the color pattern in Brachydanio rerio. J Morphol 52:513-523.

Goodrich HB, Marzullo CM, Bronson WR. 1954. An analysis of the formation of color patterns in two fresh-water fish. J Exp Zool 125:487-505.

Groves AK, Bronner-Fraser M. 1999. Neural crest diversification. Curr Topics Dev Biol 43:221-258.

Guo CS, Wehrle-Haller B, Rossi J, Ciment G. 1997. Autocrine regulation of neural crest cell development by Steel factor. Dev Biol 184:61-69.

Haldane JBS. 1932. The time of action of genes, and its bearing on some evolutionary problems. Am Nat 66:5-24.

Hall BK. 1999. The neural crest in development and evolution. New York: Springer-Verlag.

Hawkes JW. 1974. The structure of fish skin. II. The chromatophore unit. Cell Tissue Res 149:159-172.

Hemesath TJ, Price ER, Takemoto C, Badalian T, Fisher DE. 1998. MAP kinase links the transcription factor Microphthalmia to c-Kit signalling in melanocytes. Nature 391:298-301.

Henion PD, Weston JA. 1997. Timing and pattern of cell fate restriction in the neural crest lineage. Development 124:4351-4359.

Herbomel P, Thisse B, Thisse C. 2001. Zebrafish early macrophages colonize cephalic mesenchyme and developing brain, retina, and epidermis though a M-CSF receptor-dependent invasive process. Dev Biol 238:274-288

Hisaoka KK, Battle HI. 1958. The normal developmental stages of the zebrafish, Brachydanio rerio (Hamilton-Buchanan). J Morphol 102: 311-327.

Hodgkinson CA, Moore KJ, Nakayama A, Steingrimsson E, Copeland NG, Jenkins NA, Amheiter H. 1993. Mutations at the mouse microphthalmia locus are associated with defects in a gene encoding a novel basic-helix-loop-helix-zipper protein. Cell 74:395-404.

Hornyak TJ, Hayes DJ, Chiu L, Ziff EB. 2001. Transcription factors in melanocyte development: distinct roles for Pax-3 and Mitf. Mech Dev 101:47-59.

Hörstadius S. 1950. The neural crest: its properties and derivatives in light of experimental research. London: Oxford University Press.

Hosoda K, Hammer RE, Richardson JA, Baynash AG, Cheung JC, Giaid A, Yanagisawa M. 1994. Targeted and natural (piebald-lethal) mutations of endothelin-B receptor gene produce megacolon associated with spotted coat color in mice. Cell 79:1267-1276.

Hou L, Takeuchi T. 1994. Neural crest development in reptilian embryos, studied with monoclonal antibody, HNK-1. Zool Sci 11: 423-431.

Hou L, Panthier JJ, Amheiter H. 2000. Signaling and transcriptional regulation in the neural crest-derived melanocyte lineage: interactions between KIT and MITF. Development 127:5379-5389.

Houde AE. 1997. Sex, color, and mate choice in guppies. Princeton: Princeton University Press.

Hukriede NA, Joly L, Tsang M, Miles J, Tellis P, Epstein JA, Barbazuk WB, Li FN, Paw B, Postlethwait JH, Hudson TJ, Zon LI, McPherson JD, Chevrette M, Dawid IB, Johnson, SL, Ekker M. 1999. Radiation hybrid mapping of the zebrafish genome. Proc Natl Acad Sci USA 96:9745-9750.

Ide H. 1986. Transdifferentiation of amphibian chromatophores. New York: Academic Press.
Ikeya M, Lee SM, Johnson JE, McMahon AP, Takada S. 1997. Wnt signalling required for expansion of neural crest and CNS progenitors. Nature 389:966-970.

Ito M, Kawa Y, Ono H, Okura M, Baba T, Kubota Y, Nishikawa SI, Mizoguchi M. 1999. Removal of stem cell factor or addition of monoclonal anti-c-KIT antibody induces apoptosis in murine melanocyte precursors. J Invest Dermatol 112:796-801.

Jackson IJ. 1994. Molecular and developmental genetics of mouse coat color. Ann Rev Genet 28:189-217.

Jesuthasan S. 1996. Contact inhibition-collapse and pathfinding of neural crest cells in the zebrafish trunk. Development 122:381-389.

Jin EJ, Erickson CA, Takada S, Burrus LW. 2001. Wnt and BMP signaling govern lineage segregation of melanocytes in the avian embryo. Dev Biol 233:22-37.

Johnson SL, Africa D, Walker C, Weston JA. 1995. Genetic control of adult pigment stripe development in zebrafish. Dev Biol 167:27-33.

Jordan S, Jackson IJ. 2000a. MGF (KIT ligand) is a chemokinetic factor for melanoblast migration in hair follicles. Dev Biol 225:424436.

Jordan SA, Jackson IA. 2000b. A late wave of melanoblast differentiation and rostrocaudal migration revealed in patch and rumpwhite embryos. Mech Dev 92:135-143.

Kawakami K, Amsterdam A, Nobuyoshi S, Becker T, Mugg J, Shima A, Hopkins N. 2000. Proviral insertions in the zebrafish hagoromo gene, encoding an F-box/WD40-repeat protein, cause stripe pattern anomalies. Curr Biol 10:463-466.

Kelsh RN, Eisen JS. 2000. The zebrafish colourless gene regulates development of non-ectomesenchymal neural crest derivatives. Development 127:515-525.

Kelsh RN, Brand M, Jiang YJ, Heisenberg CP, Lin S, Haffter P, Odenthal J, Mullins MC, van Eeden FJM, Furutani-Seiki M, Granato M, Hammerschmidt M, Kane DA, Warga RM, Beuchle D, Vogelsang L, Nusslein-Volhard C. 1996. Zebrafish pigmentation mutations and the processes of neural crest development. Development 123:369-389.

Kelsh R N, Schmid B, Eisen JS. 2000. Genetic analysis of melanophore development in zebrafish embryos. Dev Biol 225:277-293.

Kimmel CB, Ballard WW, Kimmel SR, Ullmann B, Schilling TF. 1995. Stages of embryonic development of the zebrafish. Dev Dynamics 203:253-310.

Kirschbaum F. 1975. Untersuchungen über das Farbmuster der Zebrabarbe Brachydanio rerio (Cyprinidae, Teleostei). Wilhelm Roux's Arch 177:129-152.

Kodjabachian L, Dawid IB, Toyama R. 1999. Gastrulation in zebrafish: what mutants teach us. Dev Biol 213:231-245.

Kos R, Reedy MV, Johnson RL, Erickson CA. 2001. The winged-helix transcription factor FoxD3 is important for establishing the neural crest lineage and repressing melanogenesis in avian embryos. Development 128:1467-1479.

Kunisada T, Yoshida H, Yamazaki H, Miyamoto A, Hemmi H, Nishimura E, Shultz LD, Nishikawa S, Hayashi S. 1998. Transgene expression of steel factor in the basal layer of epidermis promotes survival, proliferation, differentiation and migration of melanocyte precursors. Development 125:2915-2923.

Lahav R, Dupin E, Lecoin L, Glavieux C, Champeval D, Ziller C, Le Douarin NM. 1998. Endothelin 3 selectively promotes survival and proliferation of neural crest-derived glial and melanocytic precursors in vitro. Proc Natl Acad Sci USA 95:14214-14219.

Lecoin L, Lahav R, Martin FH, Teillet MA, Le Douarin NM. 1995. Steel and c-kit in the development of avian melanocytes: a study of normally pigmented birds and of the hyperpigmented mutant silky fowl. Dev Dyn 203:106-118.

Lecoin L, Sakurai T, Ngo MT, Abe Y, Yanagisawa M, Le Douarin NM. 1998. Cloning and characterization of a novel endothelin receptor subtype in the avian class. Proc Natl Acad Sci USA 95:3024-3029.

Le Douarin N. 1982. The neural crest. Cambridge: Cambridge University Press.

Le Guyader S, Jesuthasan S. 2002. Analysis of xanthophore and pterinosome biogenesis in zebrafish using methylene blue and pteridine autofluorescence. Pigment Cell Res 15:27-31.

Li L. 2001. Zebrafish mutants: behavioral genetic studies of visual system defects. Dev Dyn 221:365-372.

Liem KF Jr, Tremml G, Roelink H, Jessell TM. 1995. Dorsal differentiation of neural plate cells induced by BMP-mediated signals from epidermal ectoderm. Cell 82:969-979.

Lin S, Long W, Chen J, Hopkins N. 1992. Production of germ-line chimeras in zebrafish by cell transplants from genetically pigmented to albino embryos. Proc Natl Acad Sci USA 89:4519-4523.

Lister JA, Robertson CP, Lepage T, Johnson SL, Raible DW. 1999. nacre encodes a zebrafish microphthamlia-related protein that reg- 
ulates neural crest-derived pigment cell fate. Development 126: 3757-3767.

Lister JA, Close J, Raible DW. 2001. Duplicate mitf genes in zebrafish: complementary expression and conservation of melanogenic potential. Dev Biol 237:333-344

Lopashov GV. 1944. Origins of pigment cells and visceral cartilage in teleosts. C R Acad Sci Moscow 44:169-172.

Loring JF, Erickson CA. 1987. Neural crest cell migratory pathways in the trunk of the chick embryo. Dev Biol 121:220-236.

Lu D, Willard D, Patel IR, Kadwell S, Overton L, Kost T, Luther M, Chen W, Woychik RP, Wilkison WO, Cone RD. 1994. Agouti protein is an antagonist of the melanocyte-stimulating-hormone receptor. Nature 371:799-802.

Luo R, An M, Arduini BL, Henion PD. 2001. Specific pan-neural crest expression of zebrafish Crestin throughout embryonic development. Dev Dyn 220:169-174.

Mackenzie MA, Jordan SA, Budd PS, Jackson IJ. 1997. Activation of the receptor tyrosine kinase Kit is required for the proliferation of melanoblasts in the mouse embryo. Dev Biol 192:99-107.

Mansouri A, Stoykova A, Torres M, Gruss P. 1996. Dysgenesis of cephalic neural crest derivatives in Pax $7^{-1-}$ mutant mice. Development 122:831-838.

Marklund S, Kijas J, Rodriguez-Martinez H, Ronnstrand L, Funa K, Moller M, Lange D, Edfors-Lilja I, Andersson L. 1998. Molecular basis for the dominant white phenotype in the domestic pig. Genome Res 8:826-833.

Marks SC Jr, Lane PW. 1976. Osteopetrosis a new recessive skeletal mutation on chromosome 12 of the mouse. J Hered 67:11-18.

Mayer TC. 1965. The development of piebald spotting in mice. Dev Biol 11:421-435.

McClure M. 1999. Development and evolution of melanophore patterns in fishes of the genus Danio (Teleostei: Cyprindae). J Morph 241:83-105

Metcalfe WK, Myers PZ, Trevarrow B, Bass MB, Kimmel CB. 1990. Primary neurons that express the L2/HNK-1 carbohydrate during early development in the zebrafish. Development 110:491-504.

Meyer A, Morrissey JM, Schartl M. 1994. Recurrent origin of a sexually selected trait in Xiphophorus fishes inferred from a molecular phylogeny. Nature 368:539-542.

Miller CT, Schilling TF, Lee K-H, Parker J, Kimmel CB. 2000. sucker encodes a zebrafish Endothelin-1 required for ventral pharyngeal arch development. Development 127:3815-3828.

Milos N, Dingle AD. 1978a. Dynamics of pigment pattern formation in the zebrafish, Brachydanio rerio. I. Establishment and regulation of the lateral line melanophore stripe during the first eight days of development. J Exp Zool 205:205-216.

Milos N, Dingle AD. 1978b. Dynamics of pigment pattern formation in the zebrafish, Brachydanio rerio. II. Lability of lateral line stripe formation and regulation of pattern defects. J Exp Zool 205:217224 .

Milos N, Dingle AD, Milos JP. 1983. Dynamics of pigment pattern formation in the zebrafish, Brachydanio rerio. III. Effect of anteroposterior location of three-day lateral line melanophores on colonization by the second wave of melanophores. J Exp Zool 227:81-92.

Moran NA. 1994. Adaptation and constraint in the complex life cycles of animals. Ann Rev Ecol Syst 25:573-600.

Moury JD, Jacobson AG. 1990. The origins of neural crest cells in the axolotl. Dev Biol 141:243-253.

Nguyen VH, Schmid B, Trout J, Connors SAEM, Mullins MC. 1998. Ventral and lateral regions of the zebrafish gastrula, including the neural crest progenitors, are established by a bmp $2 b /$ swirl pathway of genes. Dev Biol 199:93-110.

Nguyen VH, Trout J, Connors SA, Andermann P, Weinberg E, Mullins MC. 2000. Dorsal and intermediate neuronal cell types of the spinal cord are established by a BMP signaling pathway. Development 127:1209-1220.

Nocka K, Tan JC, Chiu E, Chu TY, Ray P, Traktman P, Besmer P. 1990. Molecular bases of dominant negative and loss of function mutations at the murine c-kit/white spotting locus: $W^{37}, W^{11}$ and $W$. EMBO J 9:1805-1813.

Oakley RA, Lasky CJ, Erickson CA, Tosney KW. 1994. Glyconjugates mark a transient barrier to neural crest migration in the chicken embryo. Development 120:103-114.

Odenthal J, Nüsslein-Volhard C. 1998. fork head domain genes in zebrafish. Dev Genes Evol 208:245-258.

Odenthal J, Rossnagel K, Haffter P, Kelsh RN, Vogelsang E, Brand M, van Eeden FJM, Furutani-Seiki M, Granato M, Hammerschmidt C-P, Jiang Y-J, Kane DA, Kelsh RN, Mullins MC, Nusslein-Volhard C. 1996. Mutations affecting xanthophore pigmentation in the zebrafish, Danio rerio. Development 123:391-398.
Okura M, Maeda H, Nishikawa S, Mizoguchi M. 1995. Effects of monoclonal anti-c-kit antibody (ACK2) on melanocytes in newborn mice. J Invest Dermatol 105:322-328.

Opdecamp K, Nakayama A, Nguyen M-T, Hogkinson CA, Pavan WJ, Arnheiter H. 1997. Melanocyte development in vivo and in neural crest cell cultures: crucial dependence on the Mitf basic-helix-loophelix-zipper transcription factor. Development 124:2377-2386.

Parichy DM. 1996a. When neural crest and placodes collide: interactions between melanophores and the lateral lines that generate stripes in the salamander Ambystoma tigrinum tigrinum (Ambystomatidae). Dev Biol 175:282-300.

Parichy DM. 1996b. Pigment patterns of larval salamanders (Ambystomatidae, Salamandridae): the role of the lateral line sensory system and the evolution of pattern-forming mechanisms. Dev Biol 175:265-282.

Parichy DM. 1996c. When neural crest and placodes collide: interactions between melanophores and the lateral lines that generate stripes in the salamander Ambystoma tigrinum tigrinum (Ambystomatidae). Dev Biol 175:283-300.

Parichy DM. 1998. Experimental analysis of character coupling across a complex life cycle: pigment pattern metamorphosis in the tiger salamander, Ambystoma tigrinum tigrinum. J Morphol 237:53-67.

Parichy DM, Rawls JF, Pratt SJ, Whitfield TT, Johnson SL. 1999. Zebrafish sparse corresponds to an orthologue of c-kit and is required for the morphogenesis of a subpopulation of melanocytes, but is not essential for hematopoiesis or primordial germ cell development. Development 126:3425-3436.

Parichy DM. 2001. Homology and evolutionary novelty in the deployment of extracellular matrix molecules during pigment pattern formation in the salamanders Taricha torosa and T. rivularis (Salamandridae). J Exp Zool 291:13-24.

Parichy DM, Johnson SL. 2001. Zebrafish hybrids suggest genetic mechanisms for pigment pattern diversification in Danio. Dev Genes Evol 211:319-328.

Parichy DM, Mellgren EM, Rawls JF, Lopes SS, Kelsh RN, Johnson SL. 2000a. Mutational analysis of endothelin receptor bl (rose) during neural crest and pigment pattern development in the zebrafish Danio rerio. Dev Biol 227:294-306.

Parichy DM, Ransom DG, Paw B, Zon LI, Johnson SL. 2000b. An orthologue of the kit-related gene $\mathrm{fms}$ is required for development of neural crest-derived xanthophores and a subpopulation of adult melanocytes in the zebrafish, Danio rerio. Development 127:30313044.

Pelletier I, Bally-Cuif L, Ziegler I. 2001. Cloning and developmental expression of zebrafish GTP cyclohydrolase I. Mech Dev 109:99-103 Perissonotto D, Iacopetti P, Bellina I, Diliana R, Colombatti A, Pettway Z, Bronner-Fraser M, Shinomura T, Kimata K, Mörgelin M, Löfberg J, Perris R. 2000. Avian neural crest cell migration is diversely regulated by the two major hyaluronan-binding proteoglycans PG-M/versican and aggrecan. Development 127:2823-2842.

Potterf SB, Furumura M, Dunn KJ, Amheiter H, Pavan WJ. 2000. Transcription factor hierarchy in Waardenburg syndrome: regulation of MITF expression by SOX10 and PAX3. Hum Genet 107:1-6. Potterf SB, Mollaaghababa R, Hou L, Southard-Smith EM, Hornyak TJ, Arnheiter H, Pavan WJ. 2001. Analysis of SOX10 function in neural crest-derived melanocyte development: SOX10-dependent transcriptional control of dopachrome tautomerase. Dev Biol 237: 245-257.

Price ER, Ding HF, Badalian T, Bhattacharya S, Takemoto C, Yao TP, Hemesath TJ, Fisher DE. 1998a. Lineage-specific signaling in melanocytes. C-kit stimulation recruits p300/CBP to microphthalmia. J Biol Chem 273:17983-17986.

Price ER, Horstmann MA, Wells AG, Weilbaecher KN, Takemoto CM, Landis MW, Fisher DE. 1998b. alpha-Melanocyte-stimulating hormone signaling regulates expression of microphthalmia, a gene deficient in Waardenburg syndrome. J Biol Chem 273:3304233047.

Raible DW, Eisen JS. 1994. Restriction of neural crest cell fate in the trunk of the embryonic zebrafish. Development 120:495-503.

Raible DW, Eisen JS. 1996. Regulative interactions in zebrafish neural crest. Development 122:501-507.

Raible DW, Wood A, Hodsdon W, Henion PD, Weston JA, Eisen JS. 1992. Segregation and early dispersal of neural crest cells in the embryonic zebrafish. Dev Dyna 195:29-42.

Rawls JF, Johnson SL. 2000. Zebrafish kit mutation reveals primary and secondary regulation of melanocyte development during fin stripe regeneration. Development 127:3715-3724.

Rawls JF, Johnson SL. 2001. Requirements for the kit receptor tyrosine kinase during regeneration of zebrafish fin melanocytes. Development 128:1943-1949. 
Rees JL. 2000. The melanocortin 1 receptor (MC1R): more than just red hair. Pigment Cell Res 13:135-140.

Reid K, Turnley AM, Maxwell GD, Kurihara Y, Kurihara H, Bartlett PF, Murphy M. 1996. Multiple roles for endothelin in melanocyte development: regulation of progenitor number and stimulation of differentiation. Development 122:3911-3919.

Richardson MK, Hornbruch A, Wolpert L. 1991. Pigment patterns in neural crest chimeras constructed from quail and guinea fowl embryos. Dev Biol 143:309-319.

Rubinstein AL, Lee D, Luo R, Henion PD, Halpern ME. 2000. Genes dependent on zebrafish cyclops function identified by AFLP differential gene expression screen. Genesis 26:86-97.

Santiago A, Erickson CA. 2002. Ephrin-B ligands play a dual role in the control of neural crest cell migration. Development 129:36213632 .

Sasai N, Mizuseki K, Sasai Y. 2001. Requirement of FoxD3-class signaling for neural crest determination in Xenopus. Development 128:2525-2536.

Schinelli S, Zanassi P, Paolillo M, Wang H, Feliciello A, Gallo V. 2001. Stimulation of endothelin $B$ receptors in astrocytes induces cAMP response element-binding protein phosphorylation and c-fos expression via multiple mitogen-activated protein kinase signaling pathways. J Neurosci 21:8842-8853.

Schmitz B, Papan C, Campos-Ortega JA. 1993. Neurulation in the anterior trunk region of the zebrafish Brachydanio rerio. Roux's Arch Dev Biol 202:250-259.

Sela-Donenfeld D, Kalcheim C. 2000. Inhibition of noggin expression in the dorsal neural tube by somitogenesis: a mechanism for coordinating the timing of neural crest emigration. Development 127: 4845-4854.

Seo HC, Saetre BO, Havik B, Ellingsen S, Fjose A. 1998. The zebrafish Pax3 and Pax7 homologues are highly conserved, encode multiple isoforms and show dynamic segment-like expression in the developing brain. Mech Dev 70:49-63

Shimoda N, Knapik EW, Ziniti J, Sim C, Yamada E, Kaplan S, Jackson D, de Sauvage F, Jacob H, Fishman MC. 1999. Zebrafish genetic map with 2000 microsatellite markers. Genomics 58:219232 .

Shin MK, Levorse JM, Ingram RS, Tilghman SM. 1999. The temporal requirement for endothelin receptor-B signalling during neural crest development. Nature 402:496-501.

Smith M, Hickman A, Amanze D, Lumsden A, Thorogood P. 1994 Trunk neural crest origin of caudal fin mesenchyme in the zebrafish Brachydanio rerio. Proc Roy Soc Lond B 256:137-145.

Southard-Smith EM, Kos L, Pavan WJ. 1998. Sox10 mutation disrupts neural crest development in DomHirschsprung mouse model. Nature Gen 18:60-64

Spritz RA. 1997. Piebaldism, Waardenburg syndrome and related disorders of melanocyte development. Semin Cut Med Surg 1:1523.

Steel KP, Davidson DR, Jackson IJ. 1992. TRP-2/DT, a new early melanoblast marker shows that steel growth factor (c-kit ligand) is a survival factor. Development 115:1111-1119.

Streisinger G, Coale F, Taggart C, Walker C, Grunwald DJ. 1989. Clonal origins of cells in the pigmented retina of the zebrafish eye. Dev Biol 131:60-69.

Sviderskaya EV, Hill SP, Balachandar D, Barsh GS, Bennett DC. 2001. Agouti signaling protein and other factors modulating differentiation and proliferation of immortal melanoblasts. Dev Dyn 221: 373-379.

Takasuka T, Sakurai T, Goto K, Furuichi Y, Watanabe T. 1994. Human endothelin receptor $\mathrm{ET}_{\mathrm{B}}$ : Amino acid sequence require- ments for super stable complex formation with its ligand. J Biol Chem 269:7509-7513.

Teitelbaum SL. 2000. Bone resorption by osteoclasts. Science 289: $1504-1508$.

Thibidaeau G, Holder S. 1998. Cellular plasticity among axolotl neural crest-derived lineages. Pigment Cell Res 11:38-44.

Thisse C, Thisse B, Postlethwait JH. 1995. Expression of snail2, a second member of the zebrafish snail family, in cephalic mesendoderm and presumptive neural crest of wild-type and spadetail mutant embryos. Dev Biol 172:86-99.

Thomas LA, Yamada KM. 1992. Contact stimulation of cell migration. J Cell Sci 103:1211-1214.

Thumann ME. 1931. Die embryonale Entwicklung des Melanophorensystems bei Brachydanio rerio (Hamilton-Buchanan). Z mikranat Forsch 25:50-96.

Trede NS, Zapata A, Zon LI. 2001. Fishing for lymphoid genes. Trends Immunol 22:302-307.

Tucker RP. 1986. The role of glycosaminoglycans in anuran pigment cell migration. J Embryol exp Morphol 92:145-164.

Tucker RP, Erickson CA. 1986a. The control of pigment cell pattern formation in the California newt, Taricha torosa. J Embryol exp Morphol 97:141-168.

Tucker RP, Erickson CA. 1986b. Pigment cell pattern formation in Taricha torosa: the role of the extracellular matrix in controlling pigment cell migration and differentiation. Dev Biol 118:268-285.

Twitty VC. 1936. Correlated genetic and embryological experiments on Triturus. I. Hybridization: Development of three species of Triturus and their hybrid combinations. II. Transplantation: The embryological basis of species differences in pigment pattern. J Exp Zool 74:239-302.

Vaglia JL, Hall BK. 2000. Patterns of migration and regulation of trunk neural crest cells in zebrafish. Int J Dev Biol 44:867-881.

Vogel G. 2000. Genomics. Sanger will sequence zebrafish genome. Science 290: 1671

Watanabe A, Takeda K, Ploplis B, Tachibana M. 1998. Epistatic relationship between Waardenburg syndrome genes MITF and PAX3. Nature Gen 18:283-286.

Wehrle-Haller B, Weston JA. 1995. Soluble and cell-bound forms of steel factor activity play distinct roles in melanocyte precursor dispersal and survival on the lateral neural crest migration pathway. Development 121:731-742.

Wehrle-Haller B, Meller M, Weston JA. 2001. Analysis of melanocyte precursors in Nf1 mutants reveals that MGF/KIT signaling promotes directed cell migration independent of its function in cell survival. Dev Biol 232:471-483.

Weilbaecher KN, Motyckova G, Huber WE, Takemoto CM, Hemesath TJ, Xu Y, Hershey CL, Dowland NR, Wells AG, Fisher DE. 2001. Linkage of M-CSF signaling to Mitf, TFE3, and the osteoclast defect in Mitf(mi/mi) mice. Mol Cell 8:749-758.

Wu M, Hemesath TJ, Takemoto CM, Horstmann MA, Wells AG, Price ER, Fisher DZ, Fisher DE. 2000. c-Kit triggers dual phosphorylations, which couple activation and degradation of the essential melanocyte factor Mi. Genes Dev 14:301-312.

Yoshida H, Kunisada T, Kusakabe M, Nishikawa S, Nishikawa S-I. 1996. Distinct stages of melanocyte differentiation revealed by analysis of nonuniform pigmentation patterns. Development 122: 1207-1214.

Ziegler I, McDonald T, Hesslinger C, Pelletier I, Boyle P. 2000. Development of the pteridine pathway in the zebrafish, Danio rerio. J Biol Chem 275:18926-18932. 